\section{Preparedness of dental graduates for foundation training: a qualitative study}

\author{
K. Ali, ${ }^{* 1}$ C. Tredwin, ${ }^{2}$ E. J. Kay, ${ }^{3}$ A. Slade ${ }^{4}$ and J. Pooler ${ }^{5}$
}

IN BRIEF
- Explores the concept of preparedness of
dental graduates for foundation training
directly with a range of stakeholders.
- Provides useful insights into the concept
of preparedness as perceived by the
stakeholders.
Offers clarity on the skills and attributes
that are essential for a smooth transition
into foundation training.

\begin{abstract}
Aims The aims of this study were to articulate the concept of preparedness of dental graduates for foundation training programme in the United Kingdom and identify the essential attributes of preparedness. Methods A qualitative approach using semi-structured interviews was used to explore the concept of preparedness. The study was carried out in the South West region of England. Participants were recruited from a range of stakeholders in dental education and foundation training using purposive sampling. Participants were recruited using email through appropriate professional channels. Stakeholders included dental students (DS), dental academics (DA), foundation dental practitioners (FDP), foundation trainers (FT), general dental practitioners (GDP) and a postgraduate dental deanery representative (DDR). Interviews were transcribed verbatim and data were imported into NVivo 9 and analysed thematically. Results Sixteen interviews were carried out with representation from all stakeholder groups. Participants expressed their views on a range of issues related to the preparedness of dental graduates. Conclusions This study provides useful insights into the concept of preparedness as perceived by the stakeholders. The findings of this study may offer clarity on the essential attributes required by dental graduates upon entry into foundation training.
\end{abstract}

\section{INTRODUCTION}

The transition into foundation training (formerly known as vocational training) programme is a challenging milestone for dental graduates in the United Kingdom. Previous studies on dental students have identified a number of deficiencies in the clinical skills of dental students. Honey et al. investigated final year dental students in performing clinical procedures using a self-assessment questionnaire. ${ }^{1}$ The students were most confident in simpler procedures like scale and polish and fissure sealants and least confident in more complex performed procedures like surgical extractions, stainless steel crowns and vital tooth bleaching. Deficiencies have also been identified in endodontics performed by dental students. Clark et al. investigated trends in teaching of complete

${ }^{1}$ Senior Lecturer in Clinical Dentistry ${ }^{2} \mathrm{Head}$ of Peninsula Dental School, ${ }^{3}$ Foundation Dean, ${ }^{5}$ Associate Research Fellow in Qualitative Methodologies, Plymouth University Schools of Medicine and Dentistry, University of Plymouth, Plymouth, PL6 8BU; ${ }^{4}$ Lecturer Occupational Health, Peninsula Allied Health Centre, Plymouth University, Plymouth, PL6 8BH

*Correspondence to: Dr Kamran Ali

Email: kamran.ali@plymouth.ac.uk

\section{Refereed Paper}

Accepted 24 April 2014

DOI: 10.1038/sj.bdj.2014.648

${ }^{\circ}$ British Dental Journal 2014; 217: 145-149 denture construction in 12 long-established dental schools. ${ }^{2}$ Responses from the lead teachers indicated that opinion was divided regarding the competence levels of students and their preparedness for foundation training. It was reported that the external examiner system, Teaching Quality Assessments and General Dental Council (GDC) visitations did not ensure GDC requirements for competence in complete denture construction were being met. Kumar et al. evaluated the technical quality endodontic treatments provided by dental students. ${ }^{3}$ Results demonstrated that the quality was judged to be acceptable in $49 \%$ of all the single-rooted teeth and only $17 \%$ of all the multi-rooted teeth.

Studies on foundation dentists have also shown that successful completion of a degree in dentistry may not necessarily equip the dental graduates with all the skills expected from them upon entry into foundation training. Buck et al. conducted a national study, involving trainers across the country, based on a postal questionnaire. ${ }^{4}$ Shortfalls were identified in areas of technical abilities (clinical skills). Patel et al. conducted a study involving 186 trainees and 186 trainers in the UK using a postal questionnaire. ${ }^{5}$ Results showed undergraduates were prepared 'well' or 'very well' to perform patient examinations, basic restorative dentistry, periodontics, and paedodontics. Undergraduate training was perceived to be inadequate in treatment planning, molar endodontics, orthodontics, complex crown and bridge work, clinical governance and practice management. Both the trainers and trainees showed a consensus that undergraduate experience of surgical extractions was either 'poor' or 'very poor'. Another area regarded as being inadequately covered during undergraduate dentistry was surgical endodontics, with both groups considering training in this area to be inadequate. Similar deficiencies have been identified in a recent national study on foundation dentists. ${ }^{6}$

Preparedness of dental graduates is an abstract concept and has been explored in a number of studies. ${ }^{1,7-9}$ However, the studies conducted so far primarily focus on identifying the magnitude of issues related to clinical skills using pre-designed questionnaires with limited opportunities for the stakeholders to articulate the essential attributes and skills expected from dental graduates. The aim of the study was to dissect the concept of preparedness of dental graduates and gain a deeper understanding to identify the essential attributes expected from a new dental graduate upon entry into foundation training. 


\section{METHODS}

Purposive sampling technique was used to engage a range of stakeholders in dental education and foundation training including dental students (DS), dental academics (DA), foundation dentists (DFT) and trainers (FT), general dental practitioners (GDP) and a representative of the dental deanery (DDR).

Following approval by the institutional Research Ethics Committee, recruitment of the participants was carried out through emails using appropriate professional channels. The dental students and academics were invited through the head of a local dental school. Foundation dentists and trainers were invited through the regional deanery. Lastly the dental practitioners were invited through the local primary care trusts.

Interviews were carried out in quiet rooms at a university in South West England. Some interviews were also conducted in a quiet room at local dental practices where some participants were based. The researcher obtained a written informed consent from each participant before commencing the interview. The role of the researcher and their professional capacity was made clear to the participants that is, the researcher is a full-time clinical academic based at a local dental school. Semi-structured interviews were used to explore the concept of preparedness. Two pilot interviews were undertaken to determine the practicalities of the interviewing process and ensure the method was appropriate to address the research questions. Sixteen participants were recruited (three participants from each of the five stakeholder groups, along with a representative of the regional deanery). The interviews were conducted between October 2012 and August 2013. The use of semi-structured interviews allowed amendments to the topic guide as relevant themes emerged; this was both during the interview itself and iteratively between the interviews.

Sixteen participants (nine males and seven females) were interviewed for this research. All interviews were recorded by digital voice recorder and transcribed verbatim, allowing double-checking of the data to ensure accuracy of transcription and subsequent coding. The typed transcript was sent to each participant to confirm its accuracy. Pseudonyms were used to protect participants' identity.

The data were analysed in NVivo 9 (QSR International Pty Ltd) using thematic analysis with an inductive approach. Initial coding of the data was carried out by systematic reading through the entire data set sentence by sentence. The initial coding yielded 130 codes. Codes were collapsed into broader categories and all the relevant coded data extracts were collated into the identified

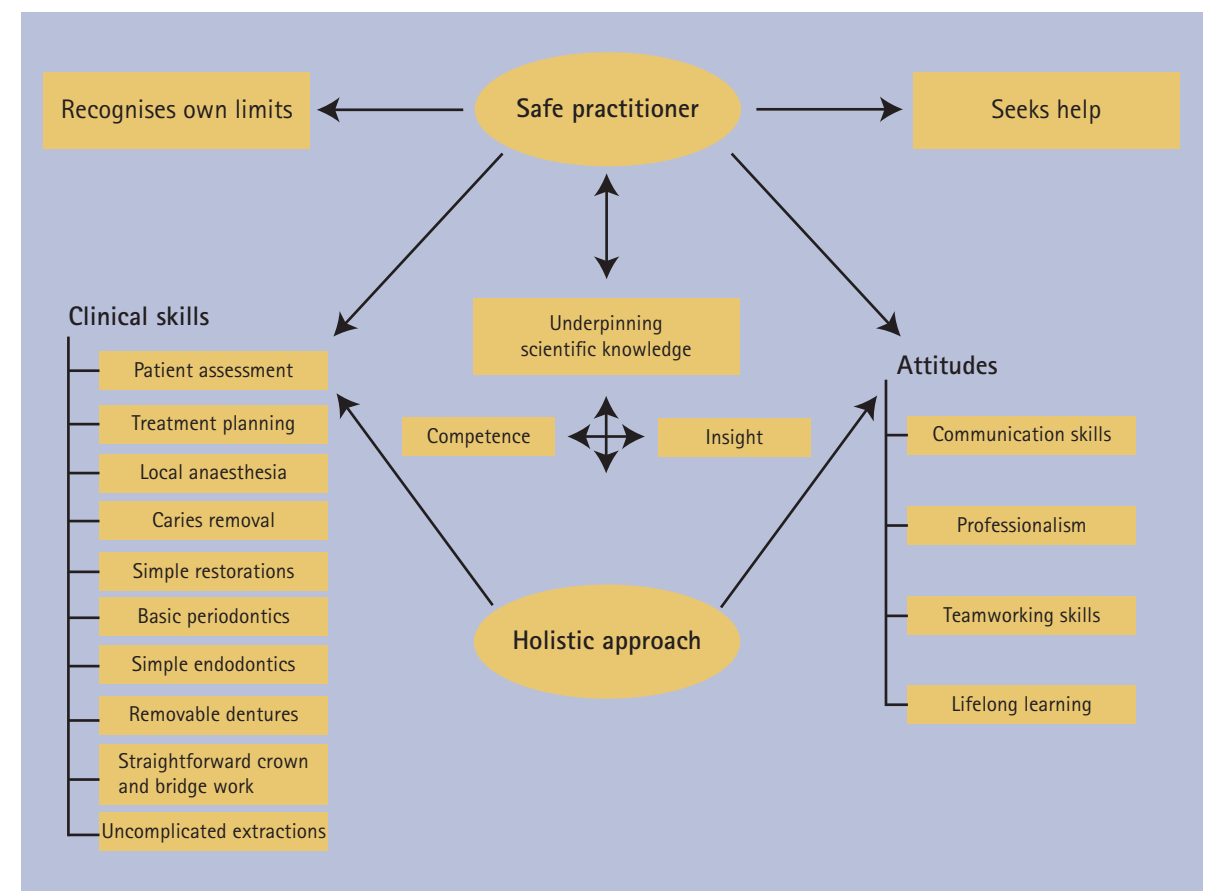

Fig. 1 The key attributes of dental graduate preparedness

themes. Member checking was done with two independent researchers to verify the seeming accuracy of the category system. Minor modifications were made to coding following member feedback and discussions. The results were shared with five participants (one participant from each stakeholder group) to ensure interpretation of the data were consistent with their views.

\section{RESULTS}

The participants expressed their views on a range of issues related to the preparedness of new graduates, reasons for gaps in training, challenges of transition, and also suggested strategies to improve preparedness. The main themes related to preparedness are discussed in this section along with excerpts from interview transcripts.

\section{Safe beginner}

Safety emerged as one of the main themes and most participants seemed to place a major emphasis on being a safe practitioner. New dental graduates need to recognise their limitations in clinical practice, seek help when things are beyond their capabilities and should refer appropriately when indicated.

'What I hope is that when you graduate, you get better at the procedures you do but the level that they want us to be is safe. So no one expects us to be restorative consultant when we leave, it's nice if we have areas which we are good at, but I think that as long as we are safe, that's the main goal.' (DS 2)

'I suppose they'll come across lots of treatments that are sort of more complex than they've attempted before and they need to know when to seek help, when to refer and whom to refer to, exactly who the people in the areas they are working are to refer to them very early.' (DA 2)

\section{Holistic care}

Dental graduates should endeavour to understand their patients, their background, and their expectations from dental treatment before focusing on specific clinical tasks.

...be able to assess them as a whole person rather than look at things in isolation, so you know looking at teeth in isolation without considering the patient's lifestyle and other previous issues, which obviously has an impact on what future treatment might be best for them.' (DS 3)

'With patient-centred, holistic approach you don't think I must deal with that aesthetic concern or that one broken tooth but take into account the whole thing, their lifestyle, their wishes, their requirements, what you can do, what your abilities are, what they can cope with.' (GDP 2)

\section{Clinical skills}

Clinical competence in a range of procedures was considered to be essential for preparedness of a new graduate. However, the majority of the participants recognised the limits of undergraduate training and emphasised achieving competence at basic, straightforward dentistry and building on these skills during foundation training and thereafter. No obvious differences were identified among various stakeholders with regard to the scope of clinical practice for a new graduate.

'I would expect them to be able to do most of procedures provided they were fairly simple and straightforward without any 
hesitation, for instance a routine, simple filling, a Class I, Class II amalgam for instance, and similarly with composites, straightforward extractions, give a local anaesthetic painlessly and confidently.' (FT 1)

'Specifically clinically, I don't know there is anything that is hugely more important than any other area. I think it's just a general experience of all the basics and it's a buildup from that.' (DFT 1)

Treatment planning skills emerged as the strongest theme within the clinical skills and most participants regarded it as one of the most important area.

'But treatment planning is the main thing. You need to know what the end result you are trying to achieve for a patient is and what you are going to do during each appointment.' (DFT 3)

'It is good that we treat patients and we take up the whole treatment plan, whatever they need because that is what the dental practice is gonna be like. We are not just gonna be turning up and doing crowns in isolation.' (DS 3)

\section{Underpinning scientific knowledge}

Dental graduates are expected to possess the scientific knowledge to support their clinical practice.

'An underpinning knowledge of what they are doing so they can base their decisions on underpinning scientific knowledge because things change so quickly because new materials come out or new techniques come out and I think they need to have an understanding how to critically appraise these new materials and new ideas.' (DA 4)

\section{Insight}

New dental graduates come with limited clinical experience and in this context confidence may be a subjective phenomenon; they need to develop an insight to identify their weaknesses and rectify them by modifying their approach.

'I think the dilemma for trainers is the unconfident trainee will ask for a lot more help and advice than the confident ones, both probably have the same needs but the other personality or insight levels of both groups vary... one may have unconscious incompetence among some of those who think they are very good whereas, perhaps those who lack self-confidence are aware they are not very good. So we are dealing with conscious incompetence.'

'Confidence may not relate to competence. It may be more of a personality trait... we've all met people who think they are absolutely wonderful and the rest of us say they won't be our clinician of choice for procedure $X$ or Y!' (DDR)

\section{Attitudes}

Another strong theme was related to attitudes. Communication and interpersonal skills, professionalism, team working and lifelong learning were identified as key attributes.

'I think communication skills is the most important skill in dentistry and if you treat your patients well and you are nice to people, you will be fine. I think if you carve beautiful amalgams, but you are not a very nice person, no one is going to come to you.' (DFT 2)

'I think communication is a huge one. The clinical things can [develop] with time, but communications is something that is important from the start.' (FT 1)

'They need to have professionalism, which for me is partly interpersonal skills, they need to get on with their team, and I think they need to learn to be a responsible person for themselves, now they've got to take on that persona of being a dentist, that everyone is looking up to them for the solution.' (DA 1)

'...working as a team, obviously the dentist is working with the nurse as a team but actually the whole practice is a team, you are there to help each other.' (DFT 2)

In summary, a prepared graduate is perceived by participants as a 'safe beginner' capable of carrying out patient assessment and treatment planning, perform routine, straightforward dental procedures safely, provide holistic care, communicate effectively, demonstrate professionalism and team-working skills, recognise their limits and know when to seek help. The key attributes of preparedness are summarised in Figure 1.

\section{DISCUSSION}

This is a pioneering study exploring the preparedness of dental graduates using qualitative methods. The theoretical framework of this study was informed by the theory of situated learning, ${ }^{10}$ which asserts that learning is intricately tied to its context and requires authentic situations and activities to facilitate learning. The data analysis of interviews is in accord in the theory of situated learning. In the context of dental education, the dental profession represents a fraternity who come together in pursuit of a shared enterprise. Data from this study underscores the role of a dental student as one of legitimate peripheral participation. ${ }^{10}$ The newcomers begin learning at the periphery of the dental community, initially by observing and later by performing basic tasks. As they become more knowledgeable and skilled, they move centrally. The student is viewed as an active participant who learns from and with the community and is at the heart of and not just a traditional apprentice whose learning may be limited to observation and imitation. ${ }^{11}$ Social interaction with the community fosters a professional identity that is akin to the acquisition of knowledge, skills and behaviours. ${ }^{12}$

The findings of this research highlight the importance of patient safety and holistic care at the heart of preparedness of new dental graduates. Patient safety is a central theme underpinning the learning outcomes of dental graduates as outlined by the GDC. ${ }^{13}$ Safe dental practice should not be solely viewed in the context of clinical procedures but should also encompass the clinician's recognition of their own limitations, seeking help and referring appropriately. Holistic patient care emerged as another strong theme. Holism in healthcare education and practice is used in multiple contexts. The recognition of holism in allopathic medicine is credited to the bio-psychosocial model presented by George Engel. ${ }^{14}$ Health problems need to be viewed in their physical, psychological, social, cultural and existential dimensions. With regard to dental practice, the clinicians need to consider a range of physical and psychosocial issues that may impact on patient care and need to plan their treatment accordingly, thereby ensuring individualised and comprehensive, patient centred care. A holistic approach to the provision of dental care is emphasised in the recent standards document published by the GDC. ${ }^{15}$

Competency-based teaching is now a well-established trend in dental schools across the UK. This study emphasises competency in a range of clinical procedures but also recognises that competency of a new dental graduate only represents a point on a continuum as highlighted previously. ${ }^{16,17}$ A new graduate will take time to develop and needs several years of exposure and experience in clinical practice settings to consolidate their knowledge, skills and attitudes. ${ }^{16,18}$ Competence in clinical practice should not be solely viewed as an achievement but rather a habit of lifelong learning. ${ }^{19}$ It has been recognised that habits of mind, behaviour and practical wisdom are gained through deliberate practice and reflection on experience. ${ }^{20}$ Students begin their training at a novice level and development of clinical competence tends to vary depending upon the context and content. ${ }^{21}$ The data analyses of interviews are in accord with the theory of situated learning and emphasise competence in basic clinical skills for a new graduate.

Treatment planning emerged as one of the most important clinical skills that underpins the preparedness of dental graduates and also one which many graduates seem to lack. Integrated treatment planning 
involves formulating a rational sequence of treatment steps designed to eliminate disease and restore efficient, comfortable, aesthetic masticatory function to a patient. ${ }^{22,23}$ Treatment planning is the central bridge that links patient assessment and diagnosis to the treatment provided. Moreover, effective treatment planning is fundamental to providing a holistic patient care, ensuring the patients receive a comprehensive continuity of care that is tailored to their individual needs and circumstances.

Treatment planning skills of undergraduate students have been long recognised as a critical component of clinical dentistry and dental education ${ }^{24}$ and are also highlighted in the learning outcomes outlined by the $\mathrm{GDC}^{13}$ and dental foundation training curriculum. ${ }^{25}$ However, few studies have explored the treatment planning skills of dental graduates and foundation trainees in UK. The relative paucity of published literature on treatment planning skills of dental students has also been identified in the USA..$^{24}$ Moreover, there seems to be an element of ambiguity in the studies reporting treatment planning skills of dental students as the term 'treatment planning' may sometimes be used in the context of planning for an individual course of treatment for example, planning a bridge or partial denture as opposed to formulating a plan for all aspects of treatment required by a patient.

The majority of new graduates in the UK have previously reported to be deficient in treatment planning skills. ${ }^{26}$ A recent study highlights that although foundation trainees fulfil expectations of their trainers in planning simple treatments, they lack in communicating the treatment plans to their patients. ${ }^{6}$ Given the departmental nature of clinical specialties in most UK dental schools, there is insufficient data to identify training and assessments of undergraduate students in treatment planning skills. Perhaps further research is required to explore teaching of treatment planning in dental schools. It is envisaged that there may possibly be a need to revisit teaching and assessments in this key area because with the departmental segregations the students may only have isolated contacts with individual patients without actually seeing them through their entire journey.

A number of previous studies exploring the preparedness of dental students and foundation trainees have used questionnaires to quantify self-confidence in various clinical skills. ${ }^{1,27}$ Data from this study suggests that confidence may relate to individual personality traits; it does not necessarily relate to competence and may in fact indicate unconscious incompetence. Confidence in dental practice skills needs to be based on experience and outcomes. Given the limited experience of students and trainees and the range of difficulty levels in clinical tasks, confidence of early learners may sometimes be misleading and needs to be interpreted with caution. Evidence from studies on medical and nursing students and junior doctors have also shown poor correlations between perceived self-confidence and observed confidence ${ }^{28-30}$ and the data from this research corroborates previous studies.

Assessment plays an integral role in helping clinicians identify and respond to their own learning needs. Assessments under examination conditions alone may not provide a reliable measure of the actual performance of students of what they actually do when not observed directly by their supervisors. The dental students and foundation trainees not only need to identify their weakness but also take appropriate remedial measures to improve performance through reflective learning. ${ }^{31,32}$ It is important to inculcate the capacity to change and improve overall performance. Dental professionals need to critically analyse their experience to understand its broader context and integrate new learning that has resulted in order to influence their future practice. This process may help them develop a professional insight into their practice, which may be more relevant than confidence. Unfortunately, there is no quick way of imparting or assessing insight and it entails going through a protracted process. Active feedback is perhaps the most crucial step in developing insight and dental educators need to monitor their students through continuous and longitudinal assessments. The theme of insight in dental practice merits further research and collaboration with professional colleagues in psychology may be appropriate to explore this further.

Management and leadership skills as highlighted by the GDC ${ }^{13}$ did surface during the interviews. However, most participants expected only a limited degree of management and leadership skills from a new dental graduate. Foundation training is a mentored year in general practice settings and the participants felt that management and leadership skills can be developed and consolidated mainly during the foundation year. These findings may be related to the fact that this study focused specifically on the "preparedness of dental graduates for foundation training,, whereas the GDC learning outcomes have been defined for independent dental practice. Nevertheless, it is recognised that these findings may generate further deliberations.

The impact of an 'insider's' influence in research remains a topic of intense debate. ${ }^{33,34}$ However, an insider researcher can offer several advantages to the quality of the study including familiarity with the research topic and better understanding of the participants to produce richer data. ${ }^{35-37}$

\section{CONCLUSION}

This study provides useful insights into the concept of preparedness as perceived by the stakeholders. A prepared graduate should be seen as 'a safe beginner' capable of carrying out patient assessment and treatment planning, perform routine, straightforward dental procedures safely, provide holistic care, communicate effectively, demonstrate professionalism and team-working skills, recognise their limits and know when to seek help. The findings of this study may offer clarity on the essential attributes required by dental graduates upon entry into foundation training and emphasise developing a range of basic skills to facilitate their transition from the dental school into foundation training programmes.

The authors would like to thank all the participants for their contribution to this research. We are also grateful to Professor David Moles, Director Postgraduate Dental Research, Peninsula Dental School and Dr Alasdair Miller, Former Postgraduate Dental Dean, South West Region for their excellent support in this research project.

1. Honey J, Lynch C D, Burke F M, Gilmour A S. Ready for practice? A study of confidence levels of final year dental students at Cardiff University and University College Cork. Eur J Dent Educ 2011; 15: 98-103.

2. Clark R K, Radford D R, Juszczyk A S. Current trends in complete denture teaching in British dental schools. Br Dent J 2010; 208: E10.

3. Kumar M, Duncan H F. Radiographic evaluation of the technical quality of undergraduate endodontic 'competence' cases in the Dublin Dental University Hospital: an audit. J Ir Dent Assoc 2012; 58: 162-166.

4. Buck D, Malik S, Murphy N et al. What makes a good dentist and do recent trainees make the grade? The views of vocational trainers. Br Dent J 2000; 189: 563-566.

5. Patel J, Fox K, Grieveson B, Youngson C C. Undergraduate training as preparation for vocational training in England: a survey of vocational dental practitioners' and their trainers' views. Br Dent J 2006; Suppl: 9-15.

6. Gilmour A, Jones R, Bullock A. Dental foundation trainers' expectations of a dental graduate: final report. Cardiff: Cardiff University, 2012. Online report available at http://www.cardiff.ac.uk/dent//resources/ ExpectationsCOPDEND2012.pdf (accessed May 2014)

7. Arena G, Kruger E, Holley D, Millar S, Tennant M. Western Australian dental graduates' perception of preparedness to practice: a five-year follow-up. J Dent Educ 2007; 71: 1217-1222.

8. Holmes D C, Diaz-Arnold A M, Williams V D. Alumni self-perception of competence at time of dental school graduation. J Dent Educ 1997; 61: 465-472.

9. Rafeek R N, Marchan S M, Naidu R S, Carrotte PV. Perceived competency at graduation among dental alumni of the University of the West Indies. J Dent Educ 2004; 68: 81-88.

10. Lave J, Wenger E. Situated learning: legitimate peripheral participation. Cambridge: Cambridge University Press, 1991

11. Mann KV. Theoretical perspectives in medical education: past experience and future possibilities. Med Educ 2011; 45: 60-68.

12. Egan $T$, Jaye $C$. Communities of clinical practice: the social organization of clinical learning. Health 2009; 
13: $107-125$

13. General Dental Council. Preparing for practice: dental team learning outcomes for registration. London: GDC, 2011.

14. Engel $G \mathrm{~L}$. The clinical application of the biopsychosocial model. Am J Psychiatry 1980; 137: 535.

15. General Dental Council. Standards for the dental team. London: GDC, 2013

16. Chambers D W. Dental curriculum and accreditation- means, ends, and the continuum. J Dent Educ 1996; 60: 816-820.

17. Harden R M. Developments in outcome-based education. Med Teach 2002; 24: 117-120.

18. Chambers D W. Problems and problem-solving strategies during the first 12 years of dental practice. J Dent Prac Admin 1989; 6: 29-34.

19. Leach D C. Competence is a habit. JAMA 2002; 287: 243-244.

20. Ericsson K A. Deliberate practice and the acquisition and maintenance of expert performance in medicine and related domains. Acad Med 2004; 79: S70-S81.

21. Epstein RM. Assessment in medical education. $N$ Engl J Med 2007; 356: 387-396.

22. Moskona D, Kaplan I, Leibovich P, Notzer N, Begleiter A. A three-year programme in oral diagnosis and treatment planning: a model using an interdisciplinary teaching team. Eur J Dent Educ 1999; 3: 27-30.
23. Wood N K, Byrne G. Treatment planning in dentistry. In Hardin J (ed) Clinical dentistry. Philadelphia: Lippincott, 1991.

24. Kennon S, Sleamaker T F Farman A G. Treatment planning instruction in North American dental schools, 1984-1985. J Dent Educ 1985; 49: 702-706.

25. Committee of Postgraduate Dental Deans and Directors UK. Interim dental foundation training curriculum and assessment framework guidance 2013-2014. COPDEND, 2013. Online guidance available at http://www.copdend.or g//data/files/ Foundation/Interim\%20DFT\%20curriculum\%20 2013-14.pdf (accessed May 2014).

26. Allen W R. Mandatory vocational training for general dental practice. Br Dent J 1993; 175: 188.

27. Manakil J, George R. Self-perceived work preparedness of the graduating dental students. Eur J Dent Educ 2013; 17: 101-105.

28. Barnsley L, Lyon P M, Ralston S J et al. Clinical skills in junior medical officers: a comparison of selfreported confidence and observed competence. Med Educ 2004; 38: 358-367.

29. Lai N M, Teng C L. Self-perceived competence correlates poorly with objectively measured competence in evidence based medicine among medical students. BMC Med Educ 2011; 11: 25.
30. Watts W E, Rush K, Wright M. Evaluating first-year nursing students' ability to self-assess psychomotor skills using videotape. Nurs Educ Perspect 2009; 30: 214-219.

31. Strauss R, Mofidi M, Sandler E S et al. Reflective learning in community-based dental education. J Dent Educ 2003; 67: 1234-1242.

32. Divaris K, Barlow P J, Chendea S A et al. The academic environment: the students' perspective. Eur J Dent Educ 2008; 1: 120-130.

33. Oliver P. Understanding the research process. London: Sage Publications, 2010.

34. Corbin Dwyer S, Buckle J. The space between: on being an insider-outsider in qualitative research International Journal of Qualitative Methods 2009: 8: 54-63.

35. Davies P. Insider research: from a position of privilege. In Paper presented at the TASA conference. (6-8 December). University of Tasmania, 2005

36. Tedlock B. Ethnography and ethnographic representation. In Denzin N K, Lincoln Y S (eds.) The handbook of qualitative research. London: Sage Publications, 2000.

37. Sunday P. The ethnographic paradigm(s). In Streubert H, Carpenter D (eds.) Qualitative research in nursing: advancing the humanistic imperative. Philadelphia: J P. Lippincott Co., 1995 